\title{
A IMPORTANCIA DE ALGUNS INDICADORES NO PROCESSO DE GESTÃO
}

Irene Caires da Silva, Sandra Cristina Pelegrini Giacomelli

Universidade do Oeste Paulista - UNOESTE, Ciências Contábeis, Presidente Prudente, SP. E-mail: irene@unoeste.br, sandrapelegrinii@hotmail.com.

\section{RESUMO}

As empresas estão constantemente em processo de tomada de decisão, seja administrativa ou financeira, buscando a consolidação no mercado em que atuam. Para extraírem informações precisas e confiáveis possuem à sua disposição indicadores capazes de traduzir em números e percentuais os resultados obtidos com suas atividades operacionais. A presente pesquisa tem como natureza bibliográfica, onde se buscou informações através de livros, artigos, periódicos entre outros. O presente artigo justifica-se pela necessidade de conhecer as ferramentas disponíveis para efetuar as análises financeiras e tem como objetivo identificar os índices mais utilizados nas análises contábeis para sanar possíveis erros que comprometam a saúde financeira da empresa e mensurar seus resultados a fim de tomar decisões assertivas quanto à sua permanência no mercado em que atua.

Palavras chave: Índices financeiros - análise - gestão - resultados - decisão

\begin{abstract}
Companies are constantly in the decision-making process, either administrative or financial , seeking consolidation in the market in which they operate. To extract accurate and reliable information they have at its disposal indicators that translate into numbers and percentages the results from its operating activities. This research is bibliographical, where we sought information through books, articles, periodicals and more. This Article is justified by the need to know the tools available to perform financial analyzes and aims to identify the most commonly used in the financial analysis indexes to remedy possible errors that compromise the financial health of the company and measure your results to make decisions assertive about their stay in the market in which it operates .
\end{abstract}

Keywords: Financial ratios - analysis - management - results - decision 


\section{INTRODUÇÃO}

As empresas são constituídas para proporcionarem a realização dos objetivos de seus proprietários, que enxergam uma oportunidade de trazer realização pessoal e profissional, tendo como resultado a obtenção de lucros e consolidação do nome no mercado de atuação.

Dessa forma, estão inseridas em um cenário dinâmico e globalizado, com ofertas diárias de novos produtos ou serviços que despertem o desejo do consumidor em comprar algo que, muitas vezes, nem pensara em adquirir.

O objetivo dos proprietários é que as empresas se consolidarem no mercado e atuem por tempo indeterminado. Mas não é bem assim que acontece. Todos os anos muitas empresas encerram suas atividades por não conseguirem cumprir o seu papel, tornando-se deficitárias em suas arrecadações não sendo capazes de arcar com suas obrigações.

Em muitos casos os proprietários são surpreendidos com situações desfavoráveis, mesmo possuindo um bom fluxo de vendas ou prestação de serviços, surgindo então os questionamentos do por que não ter dado certo, em quais pontos falharam, entre outros.

Na maioria dos casos faltou a gestão eficiente da empresa, não havendo planejamento de ações, análise dos resultados obtidos e controle das atividades operacionais desenvolvidas. Enfim, faltou utilizar as ferramentas da Administração Financeira que visam aumentar os resultados e o patrimônio da empresa por meio da geração de lucro advindos da atividade fim da empresa.

Diante deste cenário, justifica-se a necessidade de conhecer as ferramentas disponíveis para efetuar as análises financeiras a fim de produzir as mais variadas informações extraídas de índices que traduzam a real situação da empresa, sanando possíveis erros que comprometam a saúde financeira da empresa.

O presente artigo tem como objetivo identificar os índices utilizados nas análises contábeis e financeiras para que as empresas possam mensurar seus resultados e tomar decisões assertivas quanto à sua permanência no mercado em que atua.

\section{METOLOGIA}

A presente pesquisa tem como procedimento metodológico uma maneira pela qual se desenvolve as etapas da pesquisa, onde buscou primeiro entender o que é o método, sistematização e a reflexão de ideias para traçarmos o caminho da pesquisa.

Sobre a ótica de Lakatos (2010, pag.65) método, consiste em " um conjunto das atividades sistemáticas e racionais que, com maior segurança e economia, permite alcançar o objetivo - conhecimentos válidos e verdadeiros - traçando o caminho a ser seguido, detectando erros e auxiliando as decisões do cientista."

Neste sentido, a pesquisa é de natureza exploratório com abordagem qualitativa, pautando o método de pesquisa do tipo bibliográfica onde buscou-se informações para atingir o objetivo proposto. Foi viabilizada através de doutrinas, artigos científicos, periódicos, sites oficiais, dentre outros.

De acordo com Lakatos (apud ANDER - EGG, 1978, p.28) a pesquisa é um "procedimento reflexivo sistemático, controlado e crítico, que permite descobrir novos fatos ou dados, relações ou leis, em qualquer campo do conhecimento".

Por fim, pesquisa é uma maneira formal, que nos fará refletir, que necessita um tratamento científico no qual cria um caminho para conhecermos a realidade e as verdades.

\section{RESULTADO}

Os administradores necessitam de informações que evidenciam os aspectos financeiros da empresa revelando sua liquidez e estrutura, bem como precisam conhecer a situação econômica demonstrada por sua rentabilidade. Para tanto é necessário a prática de conceitos e a utilização de ferramentas de análises como os índices financeiros abordados no presente artigo. 
É de fundamental importância extrair os índices das demonstrações financeiras, realizar comparações com índices-padrões como parâmetros para mensurar os resultados obtidos, sempre considerando as particularidades de cada empresa em análise.

Após todos esses procedimentos, de posse dos resultados do estudo realizado, o gestor poderá tomar decisões assertivas, respaldadas em técnicas confiáveis.

\section{DISCUSSÃO}

As demonstrações financeiras, seguindo as regras contábeis, evidenciam dados sobre a empresa. Esses dados podem ser transformados em informações que irão orientar as decisões dos gestores, mediante a aplicação de técnicas de análises que trarão uma visão ampla e detalhada da vida da empresa, realizadas através da aplicação de indicadores econômicos e financeiros.

Ao estudarmos os índices precisamos antes conhecer os componentes do patrimônio, quer seja pessoa física ou jurídica. Assim, temos a somatória dos bens e direitos formando o grupo do ativo, onde os recursos são aplicados e o grupo do passivo composto pelas obrigações para com terceiros ou sócios. Em se tratando de empresas, as obrigações concentram as fontes de recursos utilizados para desenvolver e manter suas atividades operacionais.

Neste sentido, faz-se necessário um acompanhamento criterioso para saber quais fontes estão dando suporte ao ativo da empresa, se próprios ou de terceiros e se estão no passivo circulante ou no exigível a longo prazo. Para isso contamos com índices financeiros, que facilitarão o entendimento das demonstrações contábeis e avaliação da empresa.

Segundo Matarazzo (2010, p. 81), "índice é a relação entre contas ou grupo de contas das Demonstrações Financeiras, que visa evidenciar determinado aspecto da situação econômica ou financeira da empresa".

Não existe um número padrão para o total de índices a ser aplicado, porém é importante que seja um conjunto de índices que, ao serem aplicados juntos, consigam ampliar a visão do analista a fim de obter o maior número de informações acerca da empresa em questão.

Na contabilidade gerencial é importante que se utilize os indicadores de 10 a 20 índices e também seja realizado a analise vertical evidenciando a proporcionalidade de uma conta em relação ao todo e a analise horizontal que visualiza a evolução histórica de cada conta no transcorrer dos exercícios. De acordo com Neto (2012, p.109) a grande importância dessa técnica é bem clara: permite que se analise a tendência passada e futura de cada valor contábil. Nesse sentido, é de suma importância a utilização de todos esses elementos para analisar e emitir parecer sobre a situação econômica, financeira e patrimonial.

Para a empresa verificar a solvência se faz necessário uma mensuração da base organizacional a fim de medir o grau de solidez e analisar a situação financeira sendo empregados os índices de liquidez imediata, corrente, seca e geral sendo que quanto maiores, melhores são os seus resultados. Segundo Neto (2012, p.47) o estudo da liquidez visa conhecer a capacidade de pagamento da empresa, isto é, suas condições financeiras de cobrir no vencimento todos seus compromissos passivos assumidos.

A liquidez imediata é obtida comparando as disponibilidades da empresa e o seu passivo circulante. É um índice pouco utilizado por demonstrar um resultado muito curto. Em contrapartida temos o índice de liquidez corrente como o mais utilizado nas análises, por considerar o que a empresa possui em bens e direitos realizáveis no curto prazo, para dar suporte às suas dívidas a serem pagas no mesmo período de comparação.

São utilizados também os índices de liquidez seca que se diferenciam da corrente pelo fato de subtrair os estoques no momento de comparação. De acordo com Matarazzo (2010, p. 109) as conclusões da liquidez seca não são precisas, por isso, esse índice é utilizado como coadjuvante e não tem papel principal na avaliação da empresa: sua interpretação depende da arte e habilidade individual de quem analisa. 
A liquidez geral que traz uma visão global, indicando quanto a empresa possui de bens e direitos realizáveis no curto e longo prazo, para arcar com suas dívidas totais.

Os índices de liquidez são utilizados com frequência, mas requerem cautela, não podendo ser considerados apenas seus resultados para análise, já que os mesmos possuem limitações de informações.

As empresas analisam sua estrutura de capital contando com os índices de composição de endividamento que mostram as linhas de decisões de financiamento e de investimento. É importante acompanhar a proporção de recursos próprios e de terceiros mantidos na empresa, para analisar qual a sua dependência financeira, suas exigibilidades e seu risco. São obtidos calculando a participação de capital de terceiros, composição do endividamento, imobilização do patrimônio líquido e imobilização dos recursos não correntes.

A participação de capital de terceiros é obtida ao comparar o passivo total com o capital próprio da empresa, mostrando quanto a mesma tomou de empréstimo em relação ao capital próprio aplicado.

O endividamento geral ou dependência financeira é medido ao somar passivo circulante e não circulante e dividir esse resultado pelo ativo total da empresa.

A imobilização do patrimônio líquido é apurada pela comparação entre o ativo permanente e o passivo permanente, sendo ele o exigível a longo prazo e o patrimônio líquido, indicando qual o percentual desses recursos estão financiando o ativo permanente.

É importante também avaliar a situação econômica da empresa empregando os índices de rentabilidade dos capitais investidos e seu grau de sucesso econômico, recorrendo-se aos índices de rentabilidade ou resultados. Reis (2009, p. 288) destacou que índices de rentabilidade medem a capacidade de produzir lucro de todo o capital investido nos negócios (próprios ou de terceiros).

Os índices de rentabilidade são giro do ativo, margem líquida, rentabilidade do ativo e rentabilidade do patrimônio líquido para avaliar o desempenho da empresa, apurando qual o retorno sobre os investimentos realizados e a lucratividade obtida pelas vendas operacionais.

Desse modo, os giros do ativo no mundo dos negócios são de fundamental importância para a empresa calcular seus índices de rotação, ou seja, os prazos médios para recebimento, pagamento e giro do estoque, como destaca Matarazzo (2010, p. 11) é possível construir um modelo de análise dos investimentos e financiamento do capital de giro, de grande utilidade gerencial, bem como para a avaliação da capacidade de administração do capital de giro por parte da empresa.

O referido índice permite acompanhar o capital de giro da empresa, facilitando seu caixa e também possibilitando visualizar e obter uma margem satisfatória de lucro para dar continuidade no empreendimento.

A margem de lucro evidencia o percentual de lucro obtido com as vendas realizadas. É calculada a margem operacional comparando o lucro operacional, após a dedução de todas as despesas, excetuando-se o imposto de renda, com a receita líquida. A margem líquida é extraída da comparação do lucro líquido com a receita líquida, neste caso obtendo um resultado de lucro líquido após os impostos.

O retorno sobre o capital investido é calculado comparado o lucro operacional com o Ativo total, evidenciando o percentual de lucro produzido pelo investimento no ativo da empresa. Segundo Matarazzo (2010, p. 11), permite ampla decomposição dos elementos que influem na determinação da taxa de rentabilidade de uma empresa e explica quais os principais fatores que levaram ao aumento ou à queda de rentabilidade.

Por fim, para a empresa tomar decisões assertivas se faz necessária a aplicabilidade desses indicadores e analisar os mesmos. Assim ela poderá tomar as suas decisões embasadas nessas informações. 


\section{CONCLUSÃO}

A administração e gestão dos negócios da empresa é vital para sua consolidação no mercado em que atua, sempre se preocupando se a mesma está sendo bem administrada, se tem condições de pagar suas dívidas, se precisa contrair empréstimo junto às instituições financeiras, se necessita de novos investimentos para melhorar seu desempenho operacional, se é lucrativa e rentável, entre outros.

Para isso é fundamental adotar um sistema que controle as entradas e as saídas de caixa, seja por meio de planilhas em empresas de pequeno porte ou por meio de aplicativos elaborados em empresas maiores, mas é primordial o controle do fluxo de caixa, planejando o recebimento dos recursos e os devidos pagamentos a serem efetuados.

Faz-se necessário também a correta mensuração dos custos, a adequada elaboração do preço de venda, o estudo dos prazos para recebimentos de duplicatas, prazos pagamentos de fornecedores.

As demonstrações contábeis e financeiras evidenciam todas as operações efetuadas pela empresa, de forma ordenada e segundo critérios técnicos. Partindo desses relatórios é possível extrair um número expressivo de informações acerca das atividades desenvolvidas pela empresa, da composição de seu capital, o retorno sobre os investimentos dos empresários, entre outros.

O gestor conta com índices gerais que irão direcionar as decisões estratégicas a serem adotas mediante tomadas de decisões. Conta também com índices específicos capazes de medir aspectos econômicos e financeiros de acordo com a necessidade de cada usuário.

Por fim, o analista deverá utilizar pelo menos de 10 a 20 indicadores para poder elaborar um diagnóstico financeiro da organização com o intuito de facilitar o gerenciamento dos recursos econômicos e financeiros facilitando a empresa tomarem suas decisões e a permanência no mundo dos negócios por um longo período.

\section{REFERÊNCIAS}

LAKATOS, M. Fundamentos de Metodologia Científica. $7^{a}$ ed. (São Paulo: EDITORA ATLAS S.A, 2010.)

MARION, J. C. Contabilidade Empresarial. 15a Ed. São Paulo: Atlas, 2009.

MATARAZZO, D. C. Análise Financeira de Balanços: Abordagem Gerencial. 7ạ Ed. São Paulo: Atlas, 2010.

NETO, A.A. Estrutura e Análise de Balanços: Um enfoque Econômico-Financeiro. 10ạ Ed. São Paulo: Atlas, 2012.

REIS, A. C. R. Demonstrações Contábeis: Estrutura e Analises. 3 a Ed. São Paulo: Saraiva, 2009

SILVA, J. A. Análise Financeira das Empresas. 11ạ Ed. São Paulo: Atlas, 2012. 